Pak. j. sci. ind. res. Ser. A: phys. sci. 201356 (1) 42-46

\title{
Effect of Fibre Length on the Physical and Mechanical Properties of Sisal / Polyethylene Composites
}

\author{
Abdullahi Danladi* and Abiodun Suleiman Tunde \\ Department of Textile Science and Technology, Ahmadu Bello University, Zaria, Nigeria
}

(received April 4, 2011; revised November 30, 2011; accepted December 30, 2011)

\begin{abstract}
Composites of sisal fibres with polyethylene polymer chips were prepared at $50 \%$ fibre weight with varying lengths of the sisal fibres and the physical and mechanical properties of the composites were determined. The results of the physical properties show that moisture uptake of the composites initially increases from 0 to $60 \%$ as the fibre length increased from 0 to $5 \mathrm{~mm}$ and there after remained about the same. Density was observed to decrease initially at $5 \mathrm{~mm}$ and then steadily increased. The hardness and thickness was increased with increase in fibre length. Young's modulus, breaking load and breaking extension increased as the length of fibres in composite increased from $10 \mathrm{~mm}$ length, while work of rupture increased with increase in fibre length from about $5 \mathrm{~mm}$.
\end{abstract}

Keywords: composites, sisal fibre, fibre length, physical properties, mechanical properties.

\section{Introduction}

The interest in ligno cellulosic fibres has increased dramatically in the past few years and these fibres are now in great demand because of their attractive properties. They have become the focus of attention to scientists worldwide as they exhibit a combination of high strength with low specific gravity. Plant fibre reinforced composites prove that it is possible to construct high-performance materials with environment friendly resources. Research reported by Rowell (1998) reflects that composite materials have shown outstanding durability, corrosion resistance, lower maintenance and replacement cost, low investment in fabrication equipment, high strength to weight ratio, light weight and exceptional high formability, even at continuous high operating temperature up to $200{ }^{\circ} \mathrm{C}$. Composite materials have gained popularity in high performance products such as aerospace components (wings, tails, fuselages, and propeller), boat and scull hulls, bicycle frames and race car bodies. More uses include fishing rods and storage tanks.

Danladi (2008) reported that sisal fibre is obtained from the leaves of the plant called Sisalana (Agave sisalana), which originated from Mexico and is cultivated in East Africa, Brazil, Haiti, India, Indonesia and can also be found dispersed in Nigeria. It is grouped into the broad heading of hard fibres among which sisal is second to

*Author for correspondence; E-mail: adanladi08@gmail.com manila (obtained from the abaca plant, Musa taxtilis) in durability and strength. It is one of the most extensively cultivated plants for fibres, easily cultivated in all kind of environments. The diameter of the fibre varies from $100 \mu$ to $300 \mu$. Sisal fibre is extracted from the leaf either by scraping or retting, followed by scraping or by mechanical means i.e. decorticators.

Hawe et al. (1984) have reported the use of polyethylene for composites applications. Kumar and Sabu (1994) studied the effect of fibre length on the properties of short fibre composites and have argued that if the fibres are longer than the critical length, the strength in the composite will depend on the stressibility of the matrix or fibres. Since composite properties are affected by fibre length among other factor, this work is intended to study the effect of fibre length on the physical and mechanical properties of sisal / polyethylene composites.

\section{Materials and Methods}

Fibre extraction. The leaves from the sisal plant were crushed between pair of anvil rollers under pressure to remove the water and other liquid contents from its leaves. The remains of the crushed leaves were scraped gently with blunt knife to remove the remaining fleshy pulp. The fibres left behind were washed several times with water until a clean state was achieved, then treated in a mild solution of $0.5 \%$ caustic soda solution at a temperature of $40^{\circ} \mathrm{C}$ and finally dried. With the help of a ruler and clamp, the fibres were straightened without 
over stretching and cut into the groups of 5, 10, 15, 20, and $25 \mathrm{~mm}$ lengths.

Composites formation. About $25 \mathrm{~g}$ of the fibres were weighed out and processed with an equivalent amount of $25 \mathrm{~g}$ of polyethylene chips on a two roll mill machine at about $150{ }^{\circ} \mathrm{C}$. The sheet of composite formed was then put in a foil paper and placed between two metal sheets on a hydraulic press, at a pressure of 8psi for 3 $\min$ at $160{ }^{\circ} \mathrm{C}$. The pressed composites were then removed and the aluminum paper peeled off and allowed to cool before being cut to various shapes and sizes for analysis. The procedure was repeated for all the composites with varying sisal fibre length.

Measurements. In order to determine water absorption, $0.5 \mathrm{~g}$ of the composite from 5 different portions was kept in a glass cylinder containing water for a period of $24 \mathrm{~h}$. The samples were then removed and weighed after $24 \mathrm{~h}$ and the difference in weight was calculated using the following formula as reported in the BS (1961a; 1961b).

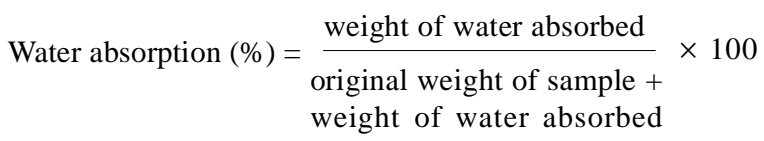

Composites density was determined by the displacement method in toluene according to BS 2011 (1961a).

The hardness measurements were carried out using a Shore A type Durometer according to ASTM D2240-03.

Composite thickness was determined by using the Martindale tester, according to BS 2023 (1961b).

Stress-strain measurements were carried out at a crosshead speed of $500 \mathrm{~mm} /$ min and gauge length of $50 \mathrm{~mm}$ on the Hounsfield Tensometer tensile strength tester with Serial No. 9873 . Ten specimens of $7 \times 1.5$ $\mathrm{cm}$ dimension were cut from each sample. The tensile strength was measured according to ASTM method D412-68.

From the plot of stress-strain curves, the mechanical properties of the composites were determined.

\section{Results and Discussion}

Effect of fibre length on moisture absorption.

Figure 1 shows that the moisture absorption of the composites increased up to $60 \%$ as the fibre length increased from 0 to $5 \mathrm{~mm}$ ( $0 \mathrm{~mm}$ means no fibre in the composites). Low density polyethylene is known to have about 0\% moisture uptake (Moncrieff, 1975).
However, as the sisal fibre is introduced, it absorbs water. According to Marjory (1972) sisal fibre has moisture uptake of about $10.5 \%$.

As the fibre length increases, the amount of water uptake can be seen to remain about the same. This implies that increasing fibre length above $5 \mathrm{~mm}$ length has no significant increase on the moisture uptake of the sisal/polyethylene composites.

Effect of fibre length on composite density. The density of the control (1000\% low density polyethylene) was seen to be about $0.94 \mathrm{~g} / \mathrm{cm}^{3}$. With the incorporation of sisal fibres of about $5 \mathrm{~mm}$ length, the density initially decreased to about $0.7 \mathrm{~g} / \mathrm{cm}^{3}$. This can be attributed to the creation of voids which formed air pockets, thus giving larger volume, which eventually lowers the density (Fig.2). As the fibre length increased, the densities of the composites were seen to increase slightly. This may be due to reduction in the voids as a result of greater fibre length in the composite structure.

Effect of fibre length on composite hardness. Since the fibre volume was kept constant at $50 \%$, the amount of fibre and polyethylene is the same. However, on increasing the fibre length, the hardness of the composites

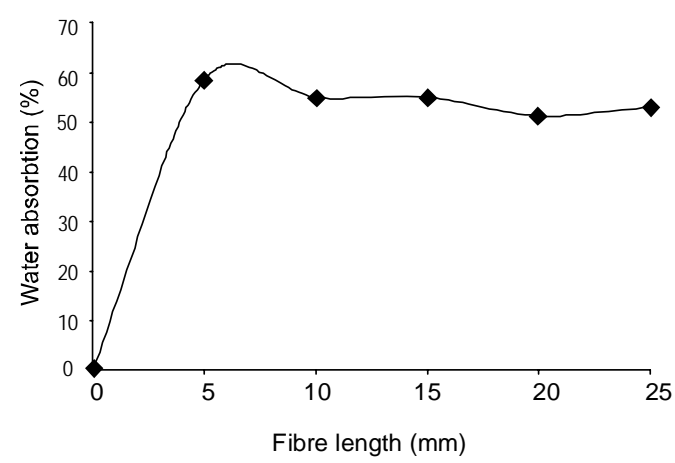

Fig. 1. Water absorption against fibre length in composite structure

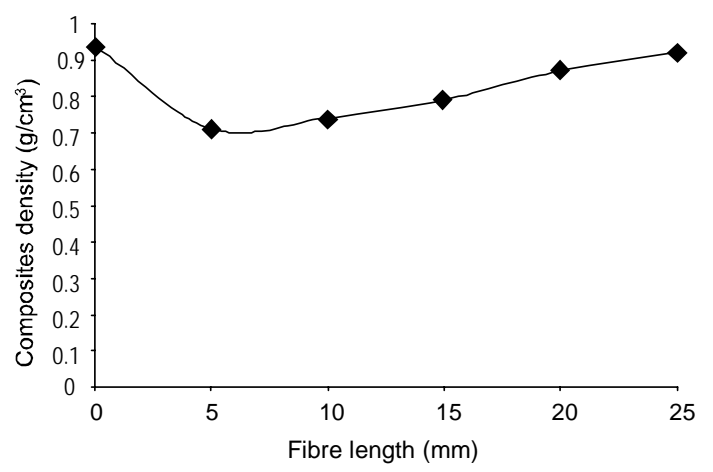

Fig. 2. Composite density against fibre length 
decreased slightly. The hardness values observed is in the range of 68 to 76 (shore) (Fig. 3). This implies that composites of sisal with low density polyethylene can be considered to have normal hardness because according to the international hardness scale, materials with hardness values of 10-35 are considered to have low hardness while those with hardness of 35-85 are classified as normal and those with hardness of 85-100 are classified as hard as reported by Singh et al (1996).

Effect of fibre length on composite hardness. The composite thickness can be seen to increase with increase in fibre length even though the fibre content by weight remains same at $50 \%$. As the fibre length increases, there is a higher possibility of the fibres coiling and congregating together, thus giving greater thickness to the composites. Generally low values of the thickness observed, suggest that these composites may probably be used as table tops in Fig. 4.

Effect of fibre length on breaking load. The breaking load of the composites was seen not to be affected by increase in fibre length from 0 to about $10 \mathrm{~mm}$. However, as the fibre length increased from about 10 to about $25 \mathrm{~mm}$, the breaking load of the composites was seen

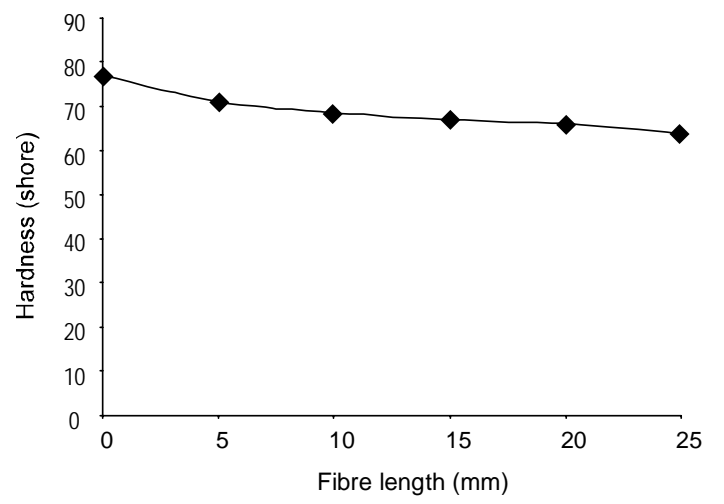

Fig. 3. Composite hardness against fibre length

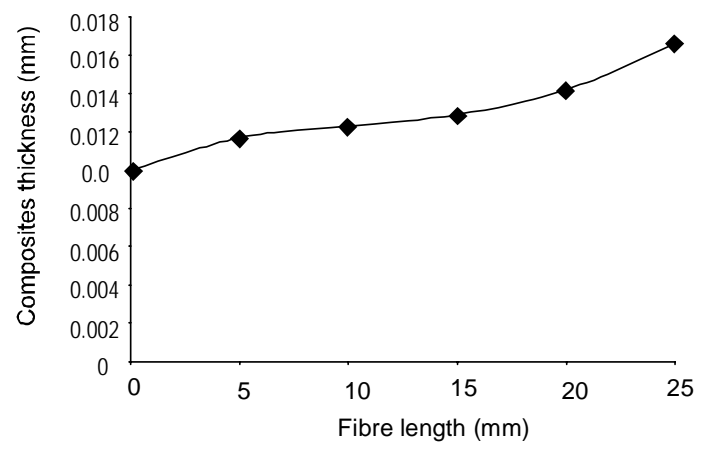

Fig. 4. Composite thickness against fibre length to increase steadily. Since breaking load indicates the maximum load a composite can bear before it is ruptured, it means that the breaking load of sisal/polyethylene composites is affected by increase in fibre length. As the fibre length and load are increased, there is more fibre length to bear the increase in load before the composite eventually fails (Fig. 5).

Effect of fibre length on breaking extension. Breaking extension is the extension of the specimen at the breaking point. From the illustrated results in Fig. 6, it can be seen that as the fibre length increased from 0 to about $20 \mathrm{~mm}$, the breaking extension increased. This observation may be attributed to the low extension values of the sisal fibres as typical of natural cellulosic fibres (Booth 1982). Since low density polyethylene as reported by Moncrieff (1975) is known to have high elongation of a )he sisal fibres therefore provide a sort of stiffening effect on their composites with low density polyethylene.

As the fibre length is increased, the low extensible fibres may have higher tendency to coil and loop in the composite structure, so when the composite is loaded, the fibres tend to stretch out resulting in the increase in the extensibility of the composites.

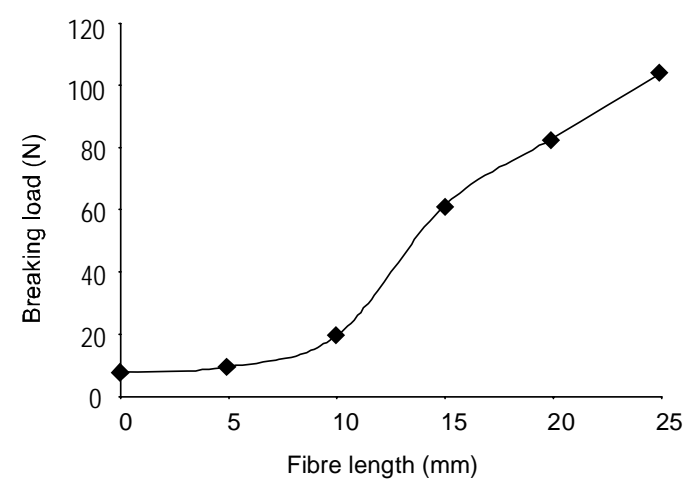

Fig. 5.Composite breaking load against fibre length

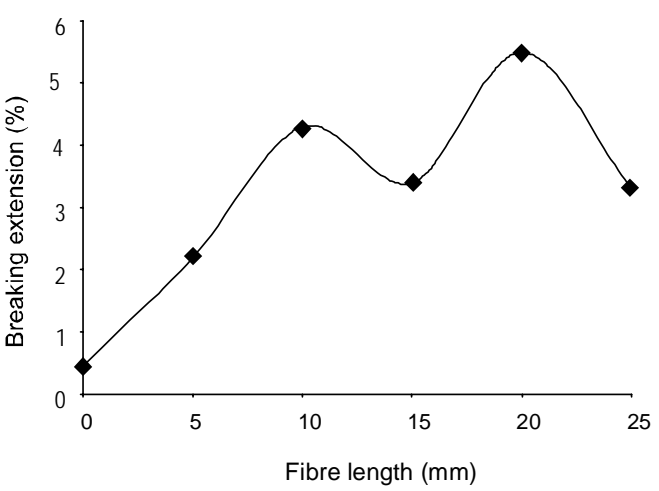

Fig. 6. Composite breaking extension against fibre length 
Effect of fibre length on Young's modulus. Initial modulus of a material tells how well the material resists deformation. High modulus indicates inextensibility while a low modulus represents great extensibility. Results in Fig. 7 show that the initial Young's modulus of the composites of sisal fibre / polyethylene composites is not affected by the fibre length as it increases from 0 to about $10 \mathrm{~mm}$. However, from $10 \mathrm{~mm}$ fibre length, the modulus values were increased. It means that these composites will have high inextensibilities, while those with less than $10 \mathrm{~mm}$ length will have high extensibility values.

Since low density polyethylene has high extensibility, it means that incorporating fibres of less than $10 \mathrm{~mm}$ length have little effect on changing the extensibility of the polyethylene matrix. Higher fibre length of sisal fibres allow for the composites to bear more load before extending, thus making them stiffer which was manifested in higher initial modulus.

Effect of fibre length on work of rupture. Work of rupture is a measure of toughness of a material. It is a measure of the energy, a material can absorb before it breaks. The area under the load-elongation or stressstrain curves represents the work done in stretching the specimen to breaking point. The higher the work of rupture of a material, the tougher is the material. Work of rupture value will indicate the resistance of the material to sudden shocks.

Figure 8 shows that as the fibre length increases from 0 to $5 \mathrm{~mm}$, the work of rupture of the composites is not affected. However, as the fibre length increased from 5 to about $25 \mathrm{~mm}$, the value of the work of rupture increased, because the load bearing capacity of composites is determined by critical fibre length (Jules et al., 2008). In this work it can be seen that $5 \mathrm{~mm}$ is

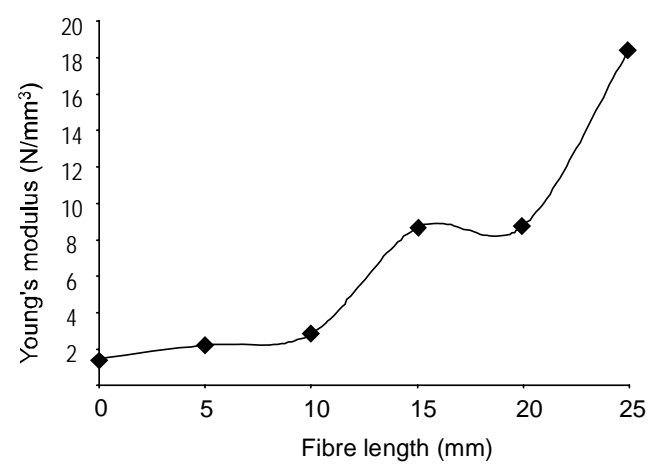

Fig. 7. Composite Young's modulus against fibre length

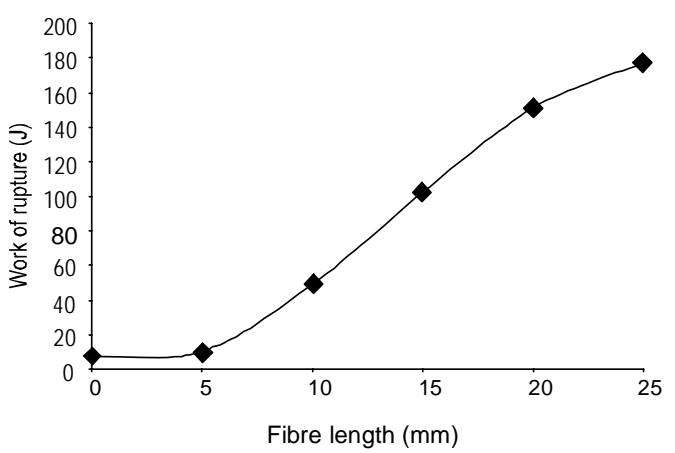

Fig. 8. Composite work of rupture against fibre length

about the critical length of the sisal fibres in these composites. Above the critical length of $5 \mathrm{~mm}$, the composites bear more loads and therefore, high work is needed to rupture the composites.

\section{Conclusion}

From the results of this work, it can be seen that composites of sisal fibres can be successfully processed at about 50\% fibre load. Most of the physical and mechanical properties studied can be seen unaffected at 0 to $10 \mathrm{~mm}$ fibre length. However, as the fibre length increases from 10 to $25 \mathrm{~mm}$, the properties are highly affected. Therefore, the critical fibre length at which composites of sisal / polyethylene composites can be produced is 10 and $25 \mathrm{~mm}$. The composites properties are promising for its consideration in many domestic operations like table tops, ceiling and partition materials.

\section{References}

Booth, J.E. 1982. Principles of Textile Testing, pp. 353455, Butterworth Scientific, London, UK.

BS. 1961a. British Standard Hand Book of Textiles, pp.124-239, Butterworth Scientific Publication, London, Retrieved August 18, 2009. http://www. amazon.co.uk/Mehods-Teest-Textiles-B-SHandbook/dp/B001O3HGLI.

BS. 1961b. British Standard Hand Book of Textiles, Butterworth Scientific Publication, London, pp. 345351. Retrieved August 18, 2009. http://www. amazon.co.uk/Mehods-Teest-Textiles-B-SHandbook/dp/B001O3HGLI.

Danladi, A., Kolawole, E.G., Bello, K.A. 2010. Physiomechanical properties of fibres from Agave sisalana (Sisal fibres). African Journal of Physical Sciences (AJPS), 8: 62-66.

Danladi, A. 2008. Characterization of some selected 
cellulosic fibres and the study of the properties of their composites with natural rubber. $P h$. D Thesis, pp. 34-97, Ahmadu Bello University, Zaria, Nigeria.

Hawe, S., Thomas, P.J., Rice, K.S. 1984, Method for preparing poly olefin composites containing a phase change material. Retrieved January 18, 2011 from http://www.patents.com/us-4908166.html. Jules, J.E., Tsujikami, T., Lomov, S.V., Verpoest, I. 2008, Effect of fibres length and fibres orientation on the predicted elastic properties of long fibre composites. Journal of Applied Polymer Science, 110: $1085-1092$.

Kumar, R.P., Sabu, T. 1994. Short fibre elastomer composites: effect of fibre length, orientation, loading and bonding agent. Bulletin of Material Science, 18: 1021-1029.
Marjory, L.J. 1972. Introductory Textiles Science, pp. 43-120, $2^{\text {nd }}$ edition, Holt, Rinchartand Inc., Winston, New York, USA.

Moncrieff, R.W. 1975. Man-made Fibres, pp. 601-608, Newness-Butterworth, London, UK.

Rowell, R.M. 1998. Property enhanced natural fiber composite materials based on chemical modification. In: Science and Technology of Polymers and Advanced Materials, Emerging Technologies and Business Opportunities, P.N. Prasad, J.E. Mark, S.H. Kandil \& Z.H. Kafafi (eds.), 717 pp., Plenum Press, New York, USA.

Singh, B., Verma, A., Gupta, M. 1996. Influence of fibres surface treatment on the properties of jutepolyester composites. Polymer Composites, 17: 910-918. 